\title{
Development of square-wave adsorptive stripping voltammetric method for determination of acebutolol in pharmaceutical formulations and biological fluids
}

\author{
Ali F Al-Ghamdi', Mohamed M Hefnawy ${ }^{2}$, Abdulrahman A Al-Majed ${ }^{2}$ and Fatallah F Belal ${ }^{3}$
}

\begin{abstract}
A validated simple, rapid, sensitive and specific square-wave voltammetric technique is described for the determination of acebutolol (AC) following its accumulation onto a hanging mercury drop electrode in a BrittonRobinson universal buffer of $\mathrm{pH} 7.5$. The optimal procedural conditions were: accumulation potential $E_{\mathrm{acc}}=-0.8 \mathrm{~V}$ versus $\mathrm{Ag} / \mathrm{AgCl} / \mathrm{KCl}$, accumulation duration $\mathrm{t}_{\mathrm{acc}}=30 \mathrm{~s}$, pulse-amplitude $=70 \mathrm{mV}$, scan rate $=100 \mathrm{mV} / \mathrm{s}$, frequency $=30 \mathrm{~Hz}$, surface area of the working electrode $=0.6 \mathrm{~mm}^{2}$ and the convection rate $=2000 \mathrm{rpm}$. Under these optimized conditions, the adsorptive stripping voltammetry (AdSV) peak current was proportional over the concentration range $5 \times 10^{-7}-6 \times 10^{-6} \mathrm{M}(r=0.999)$. Recoveries for acebutolol from human plasma and urine were in the range $97-103 \%$ and $96-104 \%$ respectively. The method proved to be precise (intra-day precision expressed as \%RSD in human plasma ranged from 2.9 - 3.2\% and inter-day precision expressed as \%RSD ranged from $3.4-3.8 \%$ ) and accurate (intra-day accuracies expressed as \% error in human urine ranged from -3.3 - 2.8\% and inter-day accuracies ranged from $-3.3-1.7 \%$ ). The limit of quantitation (LOQ) and limit of detection (LOD) for acebutolol were $1.7 \times 10^{-7}$ and $5 \times 10^{-7} \mathrm{M}$, respectively. Possible interferences by substances usually present in the pharmaceutical formulations were investigated with a mean recovery of $101.6 \pm 0.64 \%$. Results of the developed square-wave adsorptive stripping voltammetry (SW-AdSV) method were comparable with those obtained by reference analytical method.
\end{abstract}

Keywords: Acebutolol, Square wave voltammetry, Adsorptive stripping voltammetry, Pharmaceutical formulations, Biological fluids

\section{Background}

Acebotolol, (RS)-N-(3-acetyl-4-[2-hydroxy-3-(propan-2ylamino)propoxy]phenyl)butanamide is a cardioselective, lipophilic $\beta$-adrenoreceptor blocking agent with mild intrinsic sympathomimetric activity. It is therefore more suitable than non cardioselective $\beta$-blockers, if a patient with asthma or chronic obstructive pulmonary disease needs treatment with a $\beta$-blocker. It is marketed in tablets form for oral admininistration [1].Various techniques have been concerned with the development of rapid and sensitive methods for the separation, identification or

\footnotetext{
* Correspondence: mhefnawy2003@yahoo.com

2Department of Pharmaceutical Chemistry, College of Pharmacy, King Saud University, P.O. Box 2457, Riyadh 11451, Saudi Arabia

Full list of author information is available at the end of the article
}

determination of $\mathrm{AC}$ and others $\beta$-blockers in human urine. These techniques included high performance liquid chromatography (HPLC) [2,3], HPLC-mass spectrometry (MS) [4], gas chromatography-mass spectrometry (GCMS) [5] and capillary electrophoresis (CE) [6]. On the other hand, existing publications concerning the individual determination of $\mathrm{AC}$ in pharmaceutical preparations were based on, spectrophotometry [7-10], spectrofluorimetry [8], thin layer chromatography (TLC) [9], HPLC [9-11], GC [10] and CE [12]. The analytical methods reported for chiral separation of AC included CE [13-19] and HPLC [20-25]. Since, some of these methods required expensive equipment(s) and/or special treatment.

Adsorptive cathodic stripping voltammetry has been shown to be an efficient electroanalytical technique for 
the determination of sub-nanomolar levels of a wide range of drugs that have an interfacial adsorptive character onto the working electrode surface. It usually involves a simple accumulation step, and most of the excipients used do not interfere in the subsequent determination of drugs [26]. The technique is easy to use, saves of time and costs, low detection limit, high accuracy, wide concentration range, applicability to colored and turbid solution. According to our knowledge, there are only two reported papers for the determination of $\mathrm{AC}$ by the electrochemical method based on potentiometry $[27,28]$. The first reported method [27] was a coated wire electrode for some $\beta$-blockers (AC one of them) and calcium blockers has been suggested based on the use of dinonylnaphthaline sulphonic acid as ion exchanger material, the selectivity behavior was accurately predicted from calculated distribution coefficient constant for each drug. The second method [28] based on the use of ion-association complexes of $\mathrm{AC}$ with tetraphenylborate and phosphomolybdate as exchange sites in a polyvinyl chloride matrix. Therefore, there has been no report concerning the determination of AC by voltammetric method. The proposed method is a highly sensitive, simple, fast and accurate method with lower detection limits for the determination of $\mathrm{AC}$ in human plasma and urine.

\section{Experimental}

\section{Instrumentation and Chemicals}

All adsorptive stripping measurements were carried out with 797 VA Computrace (Metrohm, Switzerland) in connection with Dell computer and controlled by (VA computrace 2.0) control software. Stripping voltammograms were obtained via a HP color laserjet CP 1215 printer. A conventional three electrode system was used in the hanging mercury drop electrode (HMDE) mode. $\mathrm{pH}$ values were measured with Hanna pH 211 (Romania made). Biohit adjustable micropipette (AU), and Brand adjustable micropipette (Germany), were used to measure microliter volumes of the standard solutions. All chemicals used were of analytical reagent grade and were used without further purification. $( \pm)$ Acebutolol hydrochloride was obtained from Sigma Chemical Co. (St Louis, MO, USA). AC stock solution of $1 \times 10^{-2} \mathrm{~mol}$ $\mathrm{L}^{-1}$ was prepared by dissolving the appropriate amount of AC in methanol in $25 \mathrm{ml}$ volumetric flask and this stock solution was stored in the dark. Britton-Robinson (B-R) supporting buffer ( $\mathrm{pH} 7.5,0.04 \mathrm{M}$ in each constituent) was prepared by dissolving $2.47 \mathrm{~g}$ of boric acid (Winlab, UK) in $500 \mathrm{ml}$ distilled water containing 2.3 $\mathrm{ml}$ of glacial acetic acid (BDH, UK) and then adding 2.7 $\mathrm{ml}$ of ortho-phosphoric acid (Riedal-deHaen, Germany) and diluting to one liter with distilled water. In addition, phosphate supporting buffer $\left[0.1 \mathrm{M} \mathrm{NaH}_{2} \mathrm{PO}_{4}\right.$ (Winlab,
UK) and $0.1 \mathrm{M} \mathrm{H}_{3} \mathrm{PO}_{4}$ ] was prepared by dissolving $12 \mathrm{~g}$ of $\mathrm{NaH}_{2} \mathrm{PO}_{4}$ and $6.78 \mathrm{~g}$ of $\mathrm{H}_{3} \mathrm{PO}_{4}$ in $1000 \mathrm{ml}$ distilled water. Acetate supporting buffer $(0.02 \mathrm{M}$ in each constituent) was prepared by dissolving $1.68 \mathrm{~g}$ of sodium acetate (Winlab, UK) in $500 \mathrm{ml}$ distilled water containing $1.12 \mathrm{ml}$ of acetic acid and diluting to one liter with distilled water. Finally, carbonate supporting buffer $(0.1 \mathrm{M}$ in each constituent) was prepared by dissolving $10.6 \mathrm{~g}$ of sodium carbonate (BDH, UK) and $8.4 \mathrm{~g}$ of sodium hydrogen carbonate (Winlab, UK) in one liter distilled water.

\section{Procedures and Analysis \\ Analysis of Standard AC}

The general procedure adopted for obtaining square wave adsorptive stripping voltammograms was as follows: A $10 \mathrm{ml}$ aliquot of B-R supporting buffer (unless otherwise stated) at desired $\mathrm{pH}$ was pipetted in a clean and dry voltammetric cell and the required standard solutions of AC were added. The test solutions were purged with nitrogen for $5 \mathrm{~min}$ initially, while the solution was stirred. The accumulation potential of $-0.8 \mathrm{~V}$ vs. $\mathrm{Ag} / \mathrm{AgCl}$ was applied to a new mercury drop while the solution was stirred for $30 \mathrm{~s}$. Following the preconcentration period, the stripping was stopped and after $20 \mathrm{~s}$ had elapsed, cathodic scans were carried out over the range 0.0 to $-1.7 \mathrm{~V}$. All measurements were made at room temperature.

\section{Analysis of AC in Tablets}

Twenty tablets of Sectral ${ }^{\circledR}$ (Alexandria Pharm. \& Chem. Ind. Co., Egypt) labeled to contain $200 \mathrm{mg} \mathrm{AC}$ per tablet were powdered. An adequate amount of the homogenous powder, corresponding to $5 \times 10^{-6} \mathrm{M}$, was accurately weighed and transferred into a calibrated flask and then dissolved in $25 \mathrm{ml}$ of methanol by sonication for $10 \mathrm{~min}$, followed by mechanical shaking for $10 \mathrm{~min}$ and lastly centrifuged for $5 \mathrm{~min}$ at $10,000 \mathrm{rpm}$. A portion of the clear solution was diluted with the supporting electrolyte to achieve the desired concentration. Then AC was quantified by means of the proposed stripping voltammetric procedure.

\section{Analysis of AC in Spiked Human Plasma and Urine}

Accurately measured aliquots of AC solutions were pipette into centrifugation tubes containing $300 \mu \mathrm{l}$ human plasma and/or urine, then vortex were done for $5 \mathrm{~min}$. Into each tube, $0.5 \mathrm{ml}$ of acetontrile, $0.1 \mathrm{ml} \mathrm{NaOH}(0.1$ M), $0.5 \mathrm{ml} \mathrm{ZnSO}_{4} .7 \mathrm{H}_{2} \mathrm{O}(5 \% \mathrm{w} / \mathrm{v})$ were added, where most of the interfering substances (mainly proteins) were simply removed and eliminated by precipitation, then centrifuged for $30 \mathrm{~min}$ at $3500 \mathrm{rpm}$ [29]. The clear supernatant layer was filtered through $0.45 \mu \mathrm{m}$ Millipore filter. A $0.1 \mathrm{ml}$ volume of the supernatant liquor was transferred into the voltammetric cell then completed to a $10 \mathrm{ml}$ volume with a $\mathrm{pH} 7.5 \mathrm{~B}-\mathrm{R}$ universal 
buffer. Then AC was quantified by means of the proposed stripping voltammetric procedure.

\section{Results and Discussion}

The Electrochemical Behavior of AC

The cyclic voltammetric behavior of $5 \times 10^{-6} \mathrm{~mol} \mathrm{~L}^{-1}$ $\mathrm{AC}$ in Britton-Robinson buffer $\mathrm{pH} 7.5$ at the hanging mercury drop electrode monitored in the cathodic direction yielded a single well-defined peak at $-1237 \mathrm{mV}$ probably attributed to the cathodic reduction of the carbonyl group between the methyl and phenyl groups present in the analyte molecule (Scheme 1). No oxidation peak was observed in the positive scanning half-cycle, indicating the irreversible nature of the electrode process. The interfacial accumulation of the drug was designated from repetitive cyclic voltammograms for AC recorded following stirring for $30 \mathrm{~s}$ at $0.0 \mathrm{~V}$ prior to the first scan produced considerable cathodic peak (scan 1). As can be seen from Figure 1, a substantial decrease of the monitored electrochemical signal was observed in subsequent repetitive scans. Such behavior indicated rapid adsorption of AC from the working electrode surface. The voltammetric cycles carried out for increasing scan rate values over the range $50-500 \mathrm{mVs}^{-1}$ gave rise to an electrochemical response with increased peak current intensities. The plot of $\log i \mathrm{p}$ versus $\log v$, gave a straight line with slope value of 0.85 , which is to some degree close to the theoretical value of 1.0 that is expected for an adsorption-controlled process [30,31], indicating the interfacial adsorptive character of $\mathrm{AC}$ onto the surface electrode. In addition, the observed peak potential shift to a more negative values on the increase of scan rate confirmed the irreversible nature of the studied cathodic reduction process. The strong adsorption phenomenon of AC can be used as an effective preconcentration step prior to the actual voltammetric quantification of the analyte. The adsorptive

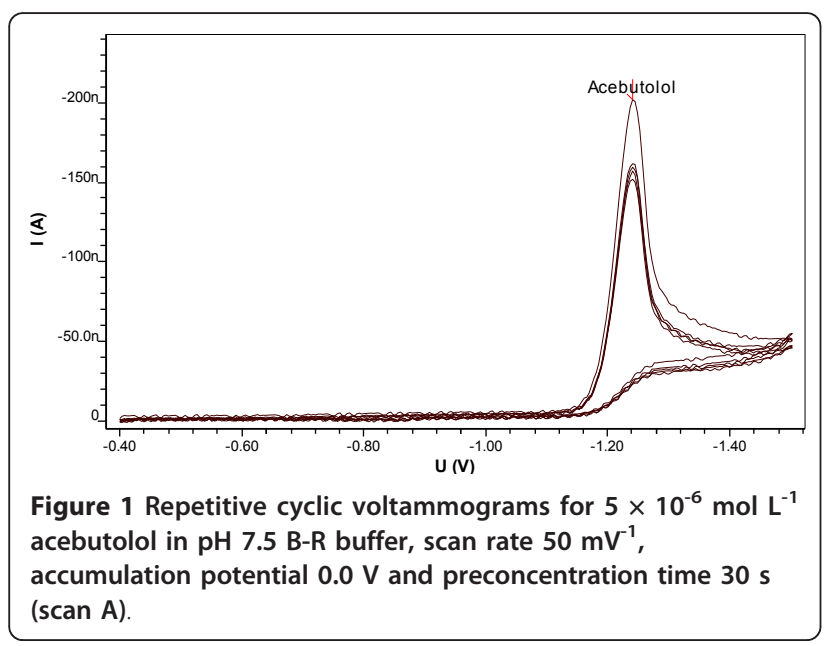

stripping voltammetric response of $\mathrm{AC}$ at HMDE was examined in Britton-Robinson buffer $\mathrm{pH} 7.5$ using the differential pulse (DP) and square wave (SW) excitation waveforms. The electrochemical current intensity for the cathodic reduction of $\mathrm{AC}$ recorded by the square wave voltammetric technique was nearly 10 times higher than that generated by the differential pulse excitation mode. Due to its intense sensitivity, therefore SWAdSV approach was used in all the subsequent experiments. Figure 2 shows a square-wave adsorptive stripping voltammogram for AC after $60 \mathrm{~s}$ accumulation period at $0.0 \mathrm{~V}$, which illustrates a single well-defined AdSV peak at $-1237 \mathrm{mV}$ versus $\mathrm{Ag} / \mathrm{AgCl}$ reference electrode.

\section{Optimum Parameters and Experimental Conditions Effect of Supporting Electrolyte and $\mathrm{pH}$}

Since the adsorptive phenomenon of AC on the HMDE was utilized as a suitable collection step prior to its electrochemical determination, it was rational to characterize various variables and experimental conditions that affecting the engaged adsorption process. In fact, the sensitivity of the adsorptive stripping procedure for a particular analyte is usually significantly influenced by the composition of the supporting buffer and $\mathrm{pH}$ value. Consequently, several supporting buffers such as Britton-Robinson, phosphate, acetate and carbonate buffers at different $\mathrm{pH}$ values were evaluated after $60 \mathrm{~s}$ accumulation time at $0.0 \mathrm{~V}$ accumulation potential. Among these supporting electrolytes the best electroanalytical signal in terms of SW-AdSV peak current intensity and shape was obtained with B-R buffer, which was selected as optimal for further works. Generally, the AdSV signal was mainly $\mathrm{pH}$ dependent since the monitored voltammetric signal was only observed at low alkaline media. When the stripping voltammetric peak current was measured as a function of $\mathrm{pH}$ over the range 5-9, the peak current increased gradually at first and enhanced

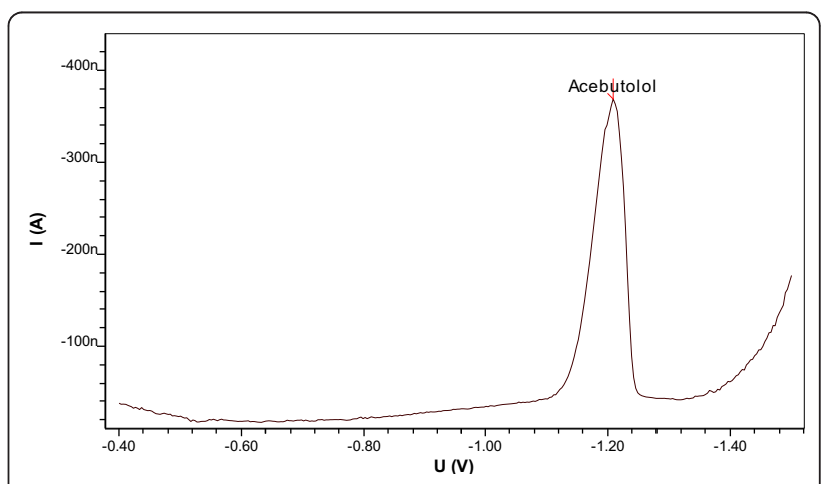

Figure 2 SW-AdSV voltammogram for acebutolol in B-R buffer (pH 7.5), $\mathrm{t}_{\mathrm{acc}}: 60 \mathrm{~s}, E_{\text {acc: }}-0.8 \mathrm{~V}$, scan rate: $100 \mathrm{mVs}^{-1}$, sW frequency: $30 \mathrm{~Hz}$ and pulse amplitude: $70 \mathrm{mV}$. acebutolol concentration: (A) $5.0 \times 10^{-6} 10 \mathrm{~mol} \mathrm{~L}^{-1}$. 
<smiles>CCCC(=O)Nc1ccc(OCC(O)CNC(C)C)c(C(C)=O)c1</smiles><smiles></smiles>

Scheme 1 Suggested mechanism of the studied electrochemical reduction process for acebutolol.

sharply beyond $\mathrm{pH} 7$ then it reached its maximum value at $\mathrm{pH} 7.5$, which was adopted as optimum $\mathrm{pH}$ value for subsequent investigations. The influence of $\mathrm{pH}$ factor on the SW-AdSV signal is illustrated in Figure 3. In addition, it was observed that the voltammetric peak potential of $\mathrm{AC}$ did not shifted when $\mathrm{pH}$ was varied over the studied $\mathrm{pH}$ rang, which indicates that $E_{\mathrm{p}}$ was $\mathrm{pH}$ independent as expected for an electrochemical reaction in which hydrogen ions did not consumed.

\section{Effect of Accumulation Time and Potential}

The interfacial accumulation of AC onto the HMDE surface depends on some operational factors, which worth additional investigations in order to ensure high sensitive determinations of AC. Therefore, the effect of accumulation time on the efficiency of the collection of $5 \times 10^{-6}$ $\mathrm{mol} \mathrm{L}^{-1} \mathrm{AC}$ onto the working electrode was evaluated by rising the accumulation time over the range $0-150 \mathrm{~s}$. The resulting peak current-accumulation time $\left(\mathrm{i}_{\mathrm{p}}-\mathrm{t}_{\mathrm{acc}}\right)$

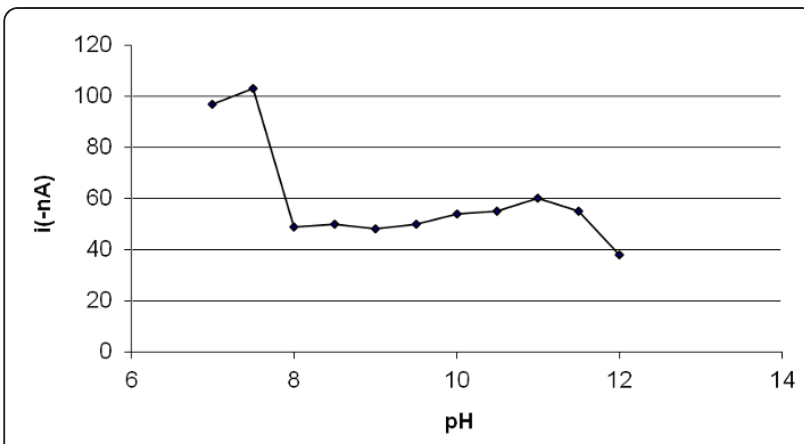

Figure 3 Effect of $\mathrm{pH}$ on SW-AdSV peak current of $5 \times 10^{-6}$ mol L $\mathrm{L}^{-1}$ acebutolol in B-R buffer after an accumulation period of $60 \mathrm{~s}$ at $\mathrm{E}_{\mathrm{acc}}=0.0 \mathrm{~V}$. profile is exhibited in Figure 4 and as can be seen from this plot, a steadily enhancement in the peak current was observed over the range 0 - $30 \mathrm{~s}$ and thereafter the peak intensity nearly decreased probably due to the saturation of the HMDE. Hence, $30 \mathrm{~s}$ accumulation times was selected for all future experiments. Furthermore, variation of the accumulation potential over the range from +0.4 to $-1.2 \mathrm{~V}$ (Figure 5) at $30 \mathrm{~s}$ accumulation time revealed that a preconcentration potential of $-0.8 \mathrm{~V}$ was the ideal choice for optimal sensitivity.

\section{Effect of Potential Sweep Conditions}

The observed stripping voltammetric signal can be further maximized by adjusting the way the applied potential was scanned. The relationship between the measured peak intensity and scan rate was found to be directly proportional over $10-100 \mathrm{mV} \mathrm{s}^{-1}$ scan arte (from studied range 10-250 $\mathrm{mV} \mathrm{s}^{-1}$ ). However, when scan rates faster than $100 \mathrm{mV} \mathrm{s}^{-1}$ were employed, the peak current decreased slightly. The influence of scan rate on the observed voltammetric signal is illustrated in Figure 6,

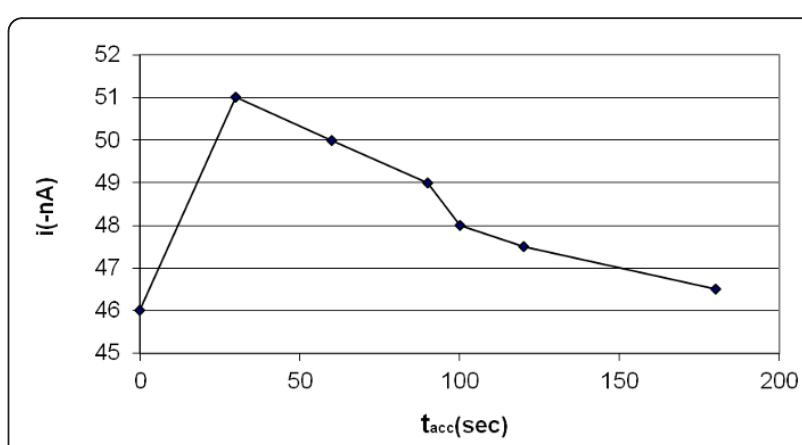

Figure 4 Effect of accumulation time on the stripping voltammetric peak current of $5 \times 10^{-6} \mathrm{~mol} \mathrm{~L}^{-1}$ acebutolol in $\mathrm{pH}$ 7.5 B-R buffer. Accumulation potential: $0.0 \mathrm{~V}$.

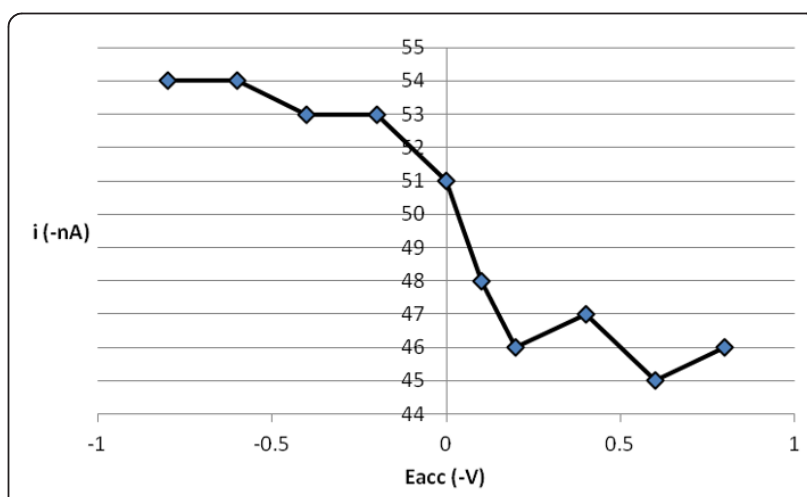

Figure 5 Effect of accumulation potential on the stripping voltammetric peak current of $5 \times 10^{-6} \mathrm{~mol} \mathrm{~L}^{-1}$ acebutolol in $\mathrm{pH}$ 7.5 B-R buffer. Accumulation time: $30 \mathrm{~s}$. 


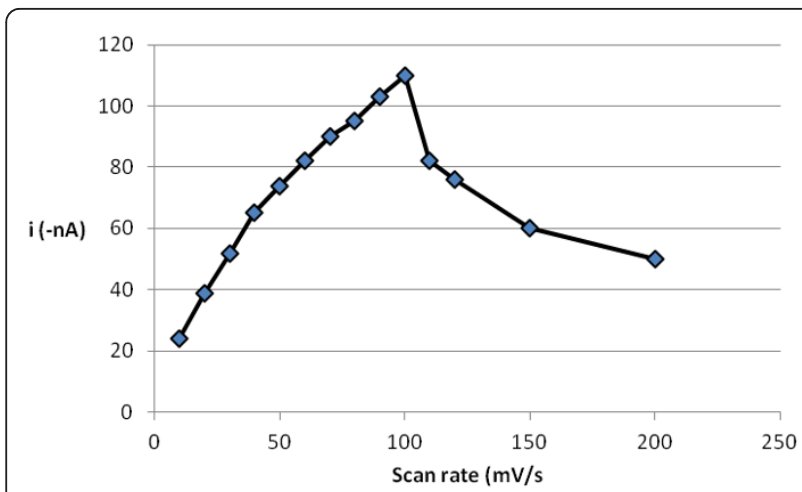

Figure 6 Effect of scan rate on AdSV peak current of $5 \times 10^{-6}$ $\mathrm{mol} \mathrm{L}^{-1}$ acebutolol in pH 7.5 B-R buffer. Accumulation time: $30 \mathrm{~s}$ and accumulation potential: $-0.8 \mathrm{~V}$.

which indicates that scan rate value of $100 \mathrm{mV} \mathrm{s}^{-1}$ would be adequate optimum for succeeding investigations.

In addition, the impact of varying the excitation wave pulse amplitude on the voltammetric current intensity was also evaluated. The effect of this operating variable was studied over the range 10-100 $\mathrm{mV}$ (Figure 7) and it was concluded that in order to assure maximum peak current, $70 \mathrm{mV}$ pulse amplitude is the ideal choice for this operational parameter. Moreover, varying the value of square wave frequency also plays an important role for the measured signal of SW-AdSV approach. Varying this parameter over the range $5-60 \mathrm{~Hz}$ resulted in a substantial enhancement of the voltammetric peak current particularly at range $5-45 \mathrm{~Hz}$ as can be seen from Figure 8, then the peak of current become constant. Accordingly, for future work $30 \mathrm{~Hz}$ SW frequency value was adopted.

\section{Effect of Other Instrumental Variables}

The influence of other operating parameters such as the size of the adsorption area (HMDE) and convection rate on the efficiency of the adsorption accumulation of AC

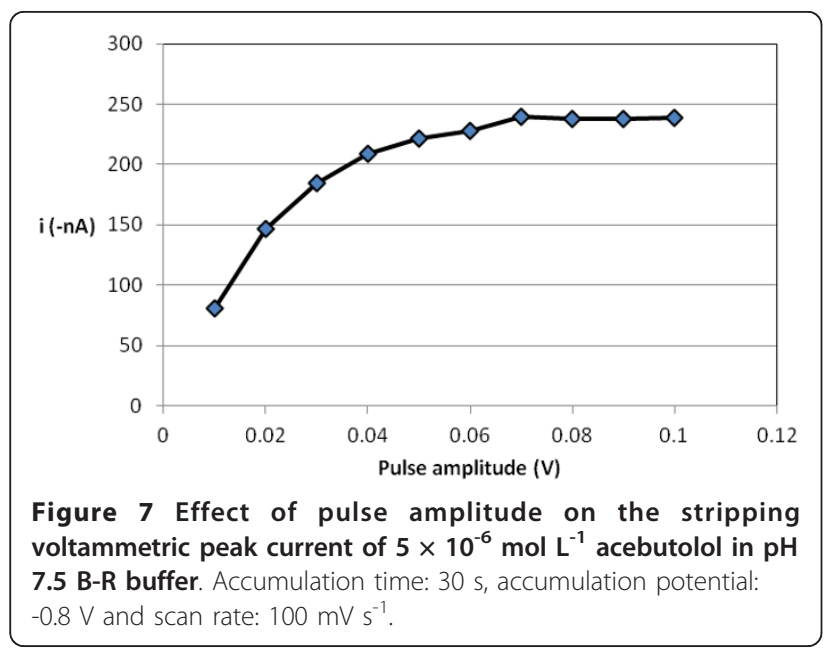

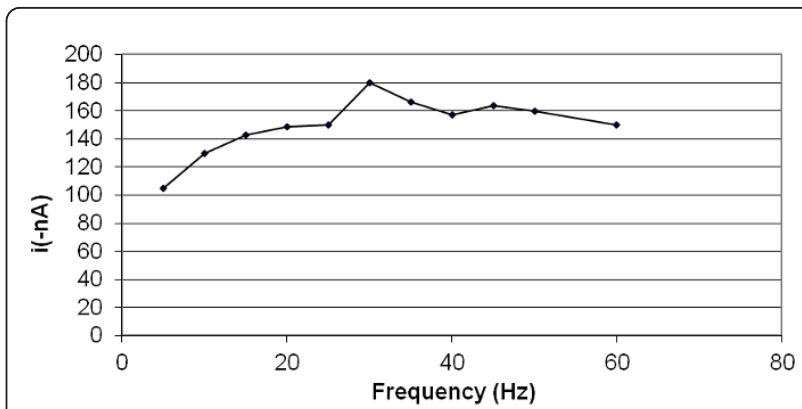

Figure 8 Effect of frequency on the stripping voltammetric peak current of $5 \times 10^{-6} \mathrm{~mol} \mathrm{~L}^{-1}$ acebutolol in $\mathrm{pH} 7.5 \mathrm{~B}-\mathrm{R}$

buffer. Accumulation time: $30 \mathrm{~s}$, accumulation potential: $-0.8 \mathrm{~V}$, scan rate: $100 \mathrm{mV} \mathrm{s}^{-1}$ and pulse amplitude $20 \mathrm{mV}$.

was additionally checked. As expected, a linear enhancement for the electrochemical peak intensity was observed when the surface area of HMDE was increased over the range $0.15-0.6 \mathrm{~mm}^{2}$ drop size area. Besides, the SW-AdSV peak current can be maximized further by increasing the stirring rate of the rotating rod over the range $0-2000 \mathrm{rpm}$. Hence, for optimal sensitivity, 0.6 $\mathrm{mm}^{2}$ drop size and $2000 \mathrm{rpm}$ stirring speed were selected.

In conclusion, for electroanalytical purposes, the optimized experimental conditions for SW-AdSV measurements of $\mathrm{AC}$ were accumulating for $30 \mathrm{~s}$ at $-8.0 \mathrm{~V}$ preconcentration potential with stirring rate of 2000 $\mathrm{rpm}$. These voltammetric measurements were carried out in Britton-Robinson buffer at pH 7.5. The applied potential was scanned at $100 \mathrm{mV} \mathrm{s}^{-1}$ with $30 \mathrm{~Hz} \mathrm{SW}$ frequency rate and $70 \mathrm{mV}$ pulse amplitude.

\section{Validation of the Method}

\section{Linearity}

Once the optimal chemical conditions and instrumental parameters for the SW-AdSV determination of AC were established, several analytical characteristics of the proposed were evaluated. Under the optimized conditions, a linear correlation between SW-AdSV peak intensity and the drug concentration was obtained over the range $5 \times 10^{-7}$ to $6 \times 10^{-6} \mathrm{~mol} \mathrm{~L}^{-1}$, (Figure 9). The calibration equation was calculated by least-squares method and it has the form:

$$
I_{p}(-n A)=2.33 \times 10^{-7} C\left(m^{-1}\right)+209.63 \quad r=0: 99, \quad n=4 .
$$

where $I_{p}$ is the stripping voltammetric peak current in nano-amperes, $\mathrm{C}$ is $\mathrm{AC}$ concentration and $\mathrm{r}$ is the correlation coefficient.

\section{Limit of quantification and limit of detection}

The limits of detection (LOD) and limits of quantification (LOQ) were determined using the formula: LOD or $\mathrm{LOQ}=k$ S.D.a $/ \mathrm{b}$, where $\mathrm{k}=3$ for LOD and 10 for 


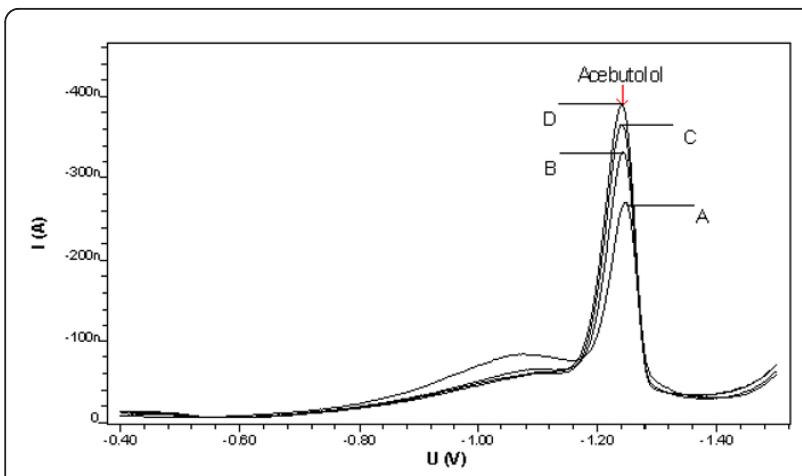

Figure 9 SW-AdSV voltammograms for Acebutolol in B-R buffer, $\mathrm{pH}=7.5, \mathrm{t}_{\mathrm{acc}}=\mathbf{3 0 \mathrm { sec }}, \mathrm{E}_{\mathrm{acc}}=-\mathbf{0 . 8 0} \mathrm{V}$, Drug Conc:- $(\mathrm{A}=$ $\left.5 \times 10^{-7} \mathrm{M}, \mathrm{B}=1 \times 10^{-6} \mathrm{M}, \mathrm{C}=3 \times 10^{-6} \mathrm{M}, \mathrm{D}=6 \times 10^{-6} \mathrm{M}\right)$

LOQ, S.D.a is the standard deviation of the intercept, and $b$ is the slope. Also lower limit of detection (LOD) defined as the concentration of AC corresponding to the intersection of the extrapolated linear segment of the calibration graph which is $1.7 \times 10^{-7} \mathrm{M}$.

This obtained sensitivity was significantly preferable than those reported for other analytical technique used for determination of $\mathrm{AC}$ such as potentiometric method [28] with $6 \times 10^{-6} \mathrm{~mol} \mathrm{~L}^{-1}$.

\section{Precision, Accuracy}

A summary of the accuracy and precision results is given in Table 1. The acceptance criteria (within-run and between-run \% RSD of less than 15\% and an accuracy between 85 and 115\%) were met in all cases. The intra-day precision and accuracy $(n=6)$ expressed as $\%$ RSD and \% error were $2.9-3.2 \%$ and $-2.5-2.0 \%$, respectively, for human plasma and $2.1-3.8 \%$ and $-3.3-2.8 \%$, respectively, for human urine. The inter-day precision and accuracy $(n=6)$ expressed as \% RSD and \% error were $3.4-3.8 \%$ and $-2.5-3.0 \%$ for human plasma, respectively, and 2.5 $4.8 \%$ and $-3.3-1.7 \%$ for human urine, respectively.

\section{Ruggedness}

The ruggedness of the SW-AdSV method was evaluated by carrying out the analysis using two different analyst (operator) and different instruments on different days. The RSD of less than $2.5 \%$ were observed for repetitive measurements in three different day time periods using two different instruments and operators. The results indicate that the method is capable of producing results with high precision.

\section{Robustness}

The robustness of the method was explained by the evaluation the influence of small variation of some of the most important procedure variables including $\mathrm{pH}$, scan rate, accumulation potential and duration. Preliminary inspection of the results under various conditions suggested that the method is fairly robust, but the $\mathrm{pH}$ of the measuring solution should be 7.5.
Table 1 Accuracy and precision data for acebutolol in spiked human plasma and urine by the proposed SWAdSV method.

\begin{tabular}{|c|c|c|c|c|}
\hline Analyte & 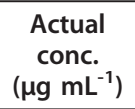 & $\begin{array}{l}\text { Experimental conc. ( } \mu \mathrm{g} \\
\mathrm{mL}^{-1} \text { ) }\end{array}$ & $\begin{array}{l}\text { RSD } \\
(\%)^{c}\end{array}$ & $\begin{array}{l}\text { Error } \\
(\%)^{d}\end{array}$ \\
\hline \multicolumn{5}{|l|}{$\begin{array}{l}\text { Intra- } \\
\text { day }^{a}\end{array}$} \\
\hline \multirow[t]{3}{*}{ Plasma } & 0.4 & $0.39 \pm 0.012$ & 3.1 & -2.5 \\
\hline & 1.0 & $0.98 \pm 0.028$ & 2.9 & -2.0 \\
\hline & 2.0 & $2.04 \pm 0.065$ & 3.2 & 2.0 \\
\hline \multirow[t]{3}{*}{ Urine } & 0.3 & $0.29 \pm 0.011$ & 3.8 & -3.3 \\
\hline & 0.9 & $0.88 \pm 0.024$ & 2.7 & -2.0 \\
\hline & 1.8 & $1.85 \pm 0.039$ & 2.1 & 2.8 \\
\hline \multicolumn{5}{|l|}{$\begin{array}{l}\text { Intra- } \\
\text { day }\end{array}$} \\
\hline \multirow[t]{3}{*}{ Plasma } & 0.4 & $0.39 \pm 0.012$ & 3.8 & -2.5 \\
\hline & 1.0 & $0.97 \pm 0.033$ & 3.4 & -3.0 \\
\hline & 2.0 & $2.06 \pm 0.072$ & 3.5 & 3.0 \\
\hline \multirow[t]{3}{*}{ Urine } & 0.3 & $0.29 \pm 0.014$ & 4.8 & -3.3 \\
\hline & 0.9 & $0.89 \pm 0.031$ & 3.5 & -1.1 \\
\hline & 1.8 & $1.83 \pm 0.045$ & 2.5 & 1.7 \\
\hline
\end{tabular}

\footnotetext{
a Mean \pm SD based on $n=6$.

${ }^{\mathrm{b}}$ Mean \pm SD based on $n=6$.

c Expressed as \% RSD: (S.D./mean) $\times 100$

${ }^{d}$ Calculated as (mean determined concentration/nominal concentration) $\times$ 100
}

\section{Selectivity}

The competitive co-adsorption interference was evaluated in the presence of various substances that are usually found in the pharmaceutical tablets and formulations. For these investigations, the interfering species were added at different concentrations (twice, 5 -fold and 50-fold) higher than the concentration of AC (5 $\times 10^{-6} \mathrm{~mol} \mathrm{~L}^{-1}$ ). The additions of filling materials (sucrose, lactose and cellulose), disintegrate agent (starch) and lubricants such as magnesium stearate caused no significant effects on the SW-AdSV response of AC. Hence, this compound may need not to be extracted from these tablet ingredients or additives prior to its determination in tablets.

\section{Analytical Applications}

Following the developed electroanalytical procedure described above, AC was analysed in pharmaceutical formulations. The AC content of commercially available tablets was determination directly by the SW-AdSV method after the required dissolving and filtration steps. Five aliquots of the dissolved sample were diluted to the required concentration level and measured via the standard additions approach. For these studies, results obtained gave a recovery mean $101.6 \%$ with standard deviation of $\pm 0.64 \%$. As can be seen from Table 2 , these results achieved by the optimized AdSV procedure were in good agreement with those obtained by 
Table 2 Comparative determination of acebutolol tablet by the proposed SW- AdSV method and the reference potentiometric method.

\begin{tabular}{|c|c|c|c|}
\hline \multicolumn{2}{|l|}{ AdSV method } & \multicolumn{2}{|c|}{ Reference method[28] } \\
\hline Found (mg) & $\%$ Recovery & Found (mg) & \% Recovery \\
\hline \multicolumn{4}{|c|}{ Labeled content of Sectral $^{\mathbb{R}}$ Tablet $^{*}$ (200 mg acebutolol) } \\
\hline 200 & 101 & 200 & 104 \\
\hline 201 & 102 & 200 & 105 \\
\hline 202 & 101 & 201 & 104 \\
\hline 202 & 102.5 & 202 & 104 \\
\hline Mean & 101.6 & Mean & 104.25 \\
\hline Standard deviation & \pm 0.64 & Standard deviation & \pm 0.43 \\
\hline
\end{tabular}

*Product of Alexandria Pharm. \& Chem. Ind. Co., Egypt.

potentiometric technique for the analysis of the same pharmaceutical tablets [28]. Based on the statistical evaluation (F-test approach) for these results, there is no significant difference between the results obtained by the developed AdSV procedure and that obtained by the reference method [28]. The calculated $\mathrm{F}$ value is 6.76 which was less than the critical value (9.28) at the $95 \%$ confidence level.

In addition, the applicability of the AdSV procedure for the analysis of $\mathrm{AC}$ in biological samples was also evaluated by estimating its recovery from spiked human urine and plasma samples. Recoveries for acebutolol from human plasma and urine were in the range 97$103 \%$ and $96-104 \%$ respectively (Table 1 ). A simple and fast pretreatment procedure [29] was used. By adding a small amount of $5 \% \mathrm{ZnSO}_{4} .7 \mathrm{H}_{2} \mathrm{O}$ solution, $\mathrm{NaOH}$ and acetonitrile to the urine or plasma samples and centrifuging the mixture, most of the interfering substances (mainly proteins) were simply removed and eliminated by precipitation (Figures 10 and 11).

\section{Conclusion}

Square-wave adsorptive stripping voltammetric (SWAdSV) method has been developed for the determination

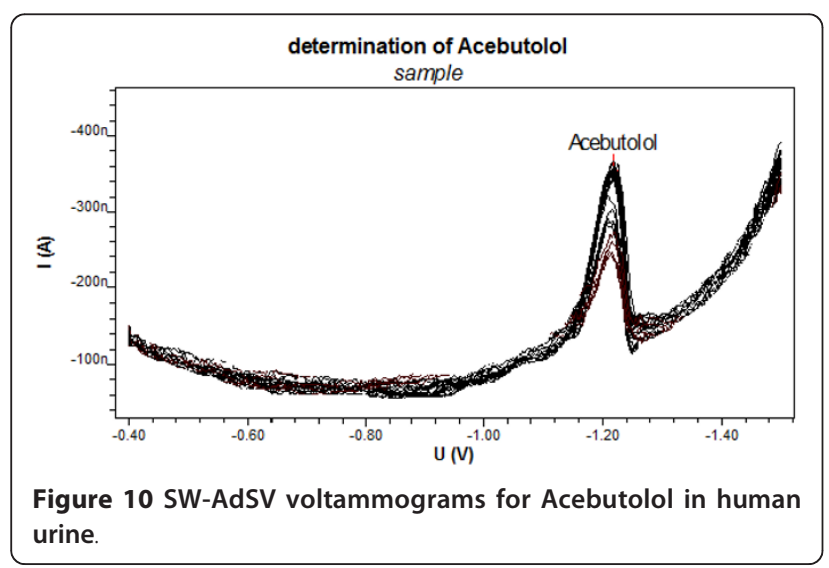

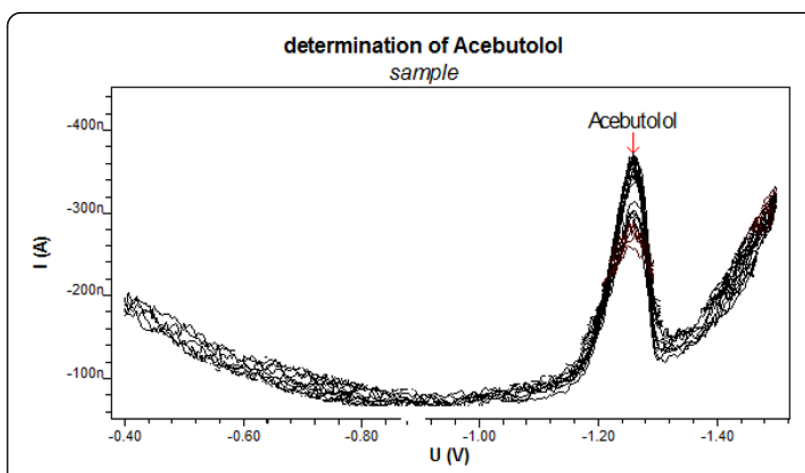

Figure 11 SW-AdSV voltammograms for Acebutolol in human plasma.

of acebutolol in biological fluids and pharmaceutical formulation for first time. The principal advantage of the proposed method over the reference potentiometric method is sensitivity and specificity. The proposed voltammetric technique has the advantages of being simpler, faster, more selective and more cost-effective than potentiometric procedure. The SW-AdSV method are rapid, requiring about $5 \mathrm{~min}$ to run sample, and involve no sample preparation other than dissolving, diluting and transferring an aliquot to the supporting electrolyte. The possibility of monitoring of the compound in human urine and plasma makes the voltammetric method useful for pharmacokinetic and pharmacodynamic purposes.

\section{Acknowledgements}

The authors extend their appreciation to the Deanship of Scientific Research at King Saud University for funding the work through the research group project no. RGP-VPP-037.

\section{Author details}

'Department of Chemistry, College of Science, Taibah University, P.O. Box 344, Al-Madinah Al-Munawarah, Saudi Arabia. ${ }^{2}$ Department of Pharmaceutical Chemistry, College of Pharmacy, King Saud University, P.O. Box 2457, Riyadh 11451, Saudi Arabia. ${ }^{3}$ Department of Analytical Chemistry, Faculty of Pharmacy, University of Mansoura, Mansoura, Egypt.

\section{Authors' contributions}

AA participated in the design of the study, carried out the experimental work and manuscript drafting. $\mathrm{MH}$ proposed and supervised the program, and participated in data analysis and draft revision. AM coordinated the study and modified the text. FB participated in the design of this study and analyzed the experimental data. All authors read and approved the final manuscript.

\section{Competing interests}

The authors declare that they have no competing interests.

Received: 21 November 2011 Accepted: 21 February 2012 Published: 21 February 2012

\section{References}

1. In Martindale: The Complete Drug Reference.. 33 edition. Edited by: Parfitt K. Pharmaceutical Press: London, UK; 2002:

2. Delamoye M, Duverneuil C, Paraire F, de Mazancourt P, Alvarez JC: Simultaneous determination of thirteen beta-blockers and one 
metabolite by gradient high-performance liquid chromatography with photodiode-array UV detection. Forensic Sci Int 2004, 141(1):23-31.

3. Saarinen MT, Sirèn $H$, Riekkola ML: Screening and determination of $\beta$ blockers, narcotic analgesics and stimulants in urine by highperformance liquid chromatography with column switching. J Chromatog B Biomed Sci Appl 1995, 664(2):341-346.

4. Pelander A, Ojanpera I, Laks S, Rasanen I, Vuori E: Toxicological screening with formula-based metabolite identification by liquid Chromatography/ time-of-flight mass spectrometry. Anal Chem 2003, 75(21):5710-5718.

5. Brunelli C, Bicchi C, Di Stilo A, Salomone A, Vincenti M: High-speed gas chromatography in doping control: fast-GC and fast-GC/MS

determination of beta-adrenoceptor ligands and diuretics. J Sep Sci 2006, 29(18):2765-2771.

6. Bai X, You TY, Sun H, Yang X, Wang E: Determination of three- $\beta$-blockers by capillary electrophoresis with end column electrochemical detection. Electroanalysis 2000, 12(8):1379-1382.

7. Sastry CS, Rao SG, Y Naidu P, Srinivas KR: New spectrophotometric method for the determination of some drugs with iodine and wool fast blue BL. Talanta 1998, 45(6):1227-1234.

8. Abdelatef HE, El-Henawee MM, El-Sayed HM, Ayad HM: Spectrophotometric and spectrofluorimetric methods for analysis of acyclovir and acebutolol hydrochloride. Spectrochim Acta A Mol Biomol Spectrosc 2006, 65(3-4):997-999

9. El-Gindy A, Ashour A, Abdel-Fattah L, Shabana MM: First derivative spectrophotometric, TLC-densitometric, and HPLC determination of acebutolol $\mathrm{HCL}$ in presence of its acid-induced degradation product. J Pharm Biomed Anal 2001, 24(4):527-534.

10. el-Walily AF: Analysis of nifedipine-acebutolol hydrochloride binary combination in tablets using UV-derivative spectroscopy, capillary gas chromatography and high performance liquid chromatography. J Pharm Biomed Anal 1997, 16(1):21-30.

11. Sanbe H, Haginaka J: Restricted access media-molecularly imprinted polymer for propranolol and its application to direct injection analysis of $\beta$-blockers in biological fluids. Analyst 2003, 128(6):593-597.

12. Pospišilová M, Kavalìrová $A$, Polášek M: Assay of acebutolol in pharmaceuticals by analytical capillary isotachophoresis. J Chromatog A 2005, 1081(1):72-76.

13. Phuong NT, Lee KA, Kim KH, Choi JK, Kim JM, Kang JS: Determination of stability constants of the inclusion complexes of beta-blockers in heptakis (2,3-dimethyl-6-sulfato)-beta-cyclodextrin. Arch Pharm Res 2004, 27(12):1290-1294.

14. Catarcini P, Fanali S, Presutti C, Dacquarica I, Gasparrini F: Evaluation of teicoplanin chiral stationary phases of 3.5 and 5 microm inside diameter silica microparticles by polar-organic mode capillary electrochromatography. Electrophoresis 2003, 24(17):3000-3005.

15. Schmid MG, Gugirz G, Kilar F: Stereoselective interaction of drug enantiomers with human serum transferrin in capillary zone electrophoresis (II). Electrophoresis 1998, 19(2):282-287.

16. Peterson AG, Foley JP: Influence of the inorganic counterion on the chiral micellar electrokinetic separation of basic drugs using the surfactant $\mathrm{N}$ dodecoxycarbonylvaline. J Chromatogr B Biomed Sci Appl 1997, 695(1):131-145.

17. Nilsson S, Schweitz L, Petersson M: Three approaches to enantiomer separation of beta-adrenergic antagonists by capillary electrochromatography. Electrophoresis 1997, 18(6):884-890

18. Kafková B, Bosáková Z, Tesarová E, Coufal P: Chiral separation of betaadrenergic antagonists, profen non-steroidal anti-inflammatory drugs and chlorophenoxypropionic acid herbicides using teicoplanin as the chiral selector in capillary liquid chromatography. J Chromatog A 2005, 1088(1-2):82-93

19. Desiderio C, Aturki Z, Fanali S: Use of vancomycin silica stationary phase in packed capillary electrochromatography I. Enantiomer separation of basic compounds. Electrophoresis 2001, 22(3):535-543.

20. Honetschlägerová-Vadinská M, Srkalová S, Bosáková Z, Coufal P, Tesarová E Comparison of enantioselective HPLC separation of structurally diverse compounds on chiral stationary phases with different teicoplanin coverage and distinct linkage chemistry. J Sep Sci 2009, 32(10):1704-1711.

21. Al-Omar MA: Stereoselective HPLC assay of acebutolol enantiomers with fluorescence detection and its application to pharmacokinetic study. World Appl Sci J 2010, 8(11):1309-1316.
22. Bosáková Z, Curínová E, Tesarová E: Comparison of vancomycin-based stationary phases with different chiral selector coverage for enantioselective separation of selected drugs in high-performance liquid chromatography. J Chromatog A 2005, 1088(1-2):94-103.

23. Jiang $H$, Randlett $C$, Junga $H$, Jiang $X$, Ji QS: Using supported liquid extraction together with cellobiohydrolase chiral stationary phasesbased liquid chromatography with tandem mass spectrometry for enantioselective determination of acebutolol and its active metabolite diacetolol in spiked human plasma. J Chromatog B Anal Techn Biomed Life Sci 2009, 877(3):173-180.

24. Kim KH, Choi PW, Hong SP, Kim HJ: Chiral separation of beta-blockers after derivatization with (-)-menthyl chloroformate by reversed-phase high performance liquid chromatography. Arch Pharml Res 1999, 22(6):608-613.

25. Szymura-Oleksiak J, Walczak M, Bojarski J, Aboul-Enein HY: Enantioselective high performance liquid chromatographic assay of acebutolol and its active metabolite diacetolol in human serum. Chirality 1999, 11(4):267-271.

26. In Analytical Electrochemistry.. 2 edition. Edited by: Wang J. Wiley-VCH, New York; 2002:

27. Cunningham $L$, Freiser $\mathrm{H}$ : On-selective electrodes for some $\beta$-adrenergic and calcium blockers. Anal Chim Acta 1984, 156:157-162.

28. Mostafa GA, Hefnawy MM, Al-Majed A: PVC membrane sensors for potentiometric determination of acebutolol. Sensors 2007, 7:3272-3286

29. Al-Ghamdi HA, Al-Ghmdi AF, Al-Omar MA: Electrochemical Studies and Square-Wave Adsorptive Stripping Voltammetry of Spironolactone Drug. Anal Lett 2008, 41(1):90-103.

30. Laviron E: A multilayer model for the study of space distributed redox modified electrodes: Part I. Description and discussion of the model. J Elec anal Chem 1980, 112:1-9.

31. Yilmaz S: Adsorptive stripping voltammetric determination of zopiclone in tablet dosage forms and human urine. Colloids Surf B Biointerfaces 2009, 71(1):79-83.

doi:10.1186/1752-153X-6-15

Cite this article as: Al-Ghamdi et al.: Development of square-wave adsorptive stripping voltammetric method for determination of acebutolol in pharmaceutical formulations and biological fluids. Chemistry Central Journal 2012 6:15.

\section{Publish with ChemistryCentral and every scientist can read your work free of charge \\ "Open access provides opportunities to our colleagues in other parts of the globe, by allowing anyone to view the content free of charge." W. Jeffery Hurst, The Hershey Company.}

- available free of charge to the entire scientific community

- peer reviewed and published immediately upon acceptance

- cited in PubMed and archived on PubMed Central

- yours - you keep the copyright

Submit your manuscript here:

http://www.chemistrycentral.com/manuscript/<smiles>c1ccccc1</smiles>

ChemistryCentral 